\title{
Setting up an outreach team in the UK
}

\author{
Kay Anderson, Dip N, RGN, CTCMH, ENB100/998, Senior Staff Nurse, Outreach, Queen Alexandra \\ Hospital, Portsmouth \\ Debbi Atkinson, BSc, RGN, RN (Child), DipHE, FAETC, ENB 125, Senior Staff Nurse, Outreach, \\ Queen Alexandra Hospital, Portsmouth
}

Jackie McBride, RGN, ENB 998, Senior Staff Nurse, Outreach, Queen Alexandra Hospital, Portsmouth

Sue Moorse, RGN, ENB 125, ENB 998, Sister, Outreach, Queen Alexandra Hospital, Portsmouth (国) Sally Smith, BSc, RGN, ENB998, Senior Staff Nurse, Outreach, Queen Alexandra Hospital, Portsmouth

Sister Sue Moorse, Outreach, Department of Critical Care, Queen Alexandra Hospital, Portsmouth PO6 3LY. e-mail: Out.Reach@qmail01.porthosp.swest.nhs.uk

\section{INTRODUCTION}

The publication of 'Comprehensive Critical Care: a review of adult critical care services’ (Department of Health, 2000) provides a plan to guide the strategic development of critical care services. The document introduces the concept of 'critical care without walls' in which the delivery of critical care is not confined to intensive care units (ICUs) but delivered according to patient need, irrespective of the location. In connection with this concept, the term 'outreach service' or 'outreach team' is used. Outreach can be described as the provision of critical care expertise to staff and patients, who are located outside the walls of the ICU. Support may take the form of direct care delivery, support, advice and/or guidance. The three major purposes of outreach can be described as:

- averting admissions to critical care units

- enabling discharges from critical care units

- sharing and development of critical care skills throughout the hospitals.

This article outlines our experiences in developing an 'outreach' service at Portsmouth Hospitals NHS Trust. In the discussion, we explore our expectations and compare these with the reality. We examine the strategies that were implemented to overcome problems we encountered.

\section{THE SETTING}

Portsmouth Hospitals NHS Trust is composed of three hospitals with a total number of 880 beds. All critical care services are based at the Queen Alexandra Hospital site. The 11-bed ICU is well-established and admits approximately 780 patients per year. A four-bed high dependency unit (HDU) was opened in 2001.

Although the Government has recommended that outreach services should be developed, each hospital is allowed to interpret this recommendation in terms of their local needs and circumstances. For example, some hospitals may choose to establish a dedicated outreach team while other hospitals may focus on using the existing ICU team to provide services, education and support. At Portsmouth, it was decided that a dedicated outreach team should be established, with nursing team members being senior nurses with an extensive range of critical care skills, proven ability to work both as an individual and within a team, and having a calm and diplomatic disposition! Our original team was comprised of three senior ICU nurses and a medical nurse practitioner. The team was later expanded to include a resuscitation training officer.

\section{ESTABLISHING THE TEAM}

In June 2000, the first member of the outreach team was identified from within the senior nurse group on ICU. During the next four months, nurses working within the Trust with an expanded role, such as accident and emergency (A\&E) nurse practitioners, resuscitation training officers or nurse clinicians, were contacted to explore their perception of the role of an outreach team. These discussions served to ensure that the new service would complement the provision which already existed. Specific expertise in the setting up of a new service was obtained from an A\&E sister who had recently managed a project to develop a nurse-led minor injury department.

A random selection of ward nurses were approached for their opinions on how an outreach team would be perceived by nurses working on the wards and what they thought outreach would be able to offer them. Without exception, this small cohort responded favourably to the idea that an outreach team would provide a supportive and advisory service to supplement the care already being delivered on the ward.

Information was sought from other outreach teams in terms of how they were developing. Accessing the internet to search for information proved fruitless, as outreach is a new concept which has not been widely explored or reported. There was some 
literature on medical emergency teams (MET) in the USA and Australia, but these operated with a very different remit to the one envisaged for our own team. We had visualised an outreach team that would adopt a supportive, advisory and educational role. Other hospitals advertising outreach vacancies were also contacted to discuss the criteria and rationale they had established for team members and how they foresaw the role developing. The critical care nurse consultant and outreach team at an adjacent Trust, who were three months ahead of us in their development, provided advice and support. Additional networking using the British Association of Critical Care Nursing (BACCN) website and message-board provided us with some information.

From December 2000, all nurse members of the team were released from off-duty rosters to concentrate on developing the service. This gave the nurses time to:

- establish referral criteria

- develop referral and follow-up processes

- develop referral and follow-up documentation

- arrange meetings with the multidisciplinary professions

- develop as a team.

Advice was sought from the ICU senior nurse and clinical director, the director of nursing and the critical care medical staff, for support in both setting up the team and the processes within which the team would operate. Discussion with this group raised some contentious issues, e.g. what could the outreach nurses actually do? Would outreach be purely for nursing advice? Would outreach nurses have prescribing powers? The outreach team and senior members of the hospital have had to work through these issues; some are yet to be resolved.

\section{EDUCATIONAL DEVELOPMENT OF THE TEAM}

Development of the outreach team involved both a formal and an informal education programme. This began with a 12-week 'physical assessment and history-taking course' (based on Jarvis 2000), run by Southampton University Hospital. The course provided a firm foundation in physical examination and clinical assessment of patients. As intensive care nurses, we were familiar with using 'high-tech machinery' to assist in patient assessment; the course developed and refined our clinical skills in patient assessment. All team members undertook and became trainers on the ALERT course (Acute Life-threatening Events Recognition and Treatment). This was particularly important as the course provided opportunities for all members of the multidisciplinary team to develop knowledge and skills in recognising deterioration in a patient's condition and to respond appropriately. A study day exploring the assessment and management of pain-facilitated liaison with other specialist nurses raised our awareness of ward procedures. The pain team identified areas where they were often asked to give advice; these were non-pain related issues further highlighting the need for the outreach team.

In addition to the formal education package, we spent time with other members of the multidisciplinary team who further assisted in enhancing our knowledge. Members of our team gained clinical experience with the already established outreach service at Southampton. We worked with some members of their team to gain insight into the developing role of the outreach nurse, while fostering closer links and facilitating an exchange of information between the two Trusts.

In addition, the medical nurse practitioner had a tailormade orientation programme designed to allow the development and enhancement of critical care skills. The three ICU nurses gained clinical experience within the ward environment.

\section{INTRODUCTION OF THE OUTREACH SERVICE}

In order to ensure successful utilisation of the service, we had to be consistent in our availability and approach. After reviewing the ICU referral data, we recognised that 24-hour cover would be the ideal model for an outreach team in Portsmouth. The team looked into the feasibility of providing 24-hour cover, but this was not possible with only four people. However, it was possible to provide cover from 7.15 am to $9.30 \mathrm{pm}$, seven days a week. In covering these hours, it usually meant only one nurse per shift, which was thought to be isolating. Thus, once per week, two nurses were rostered to work together to allow reflection on practice and clinical supervision. To cover staff sickness and absence, members of the intensive care nursing team who had successfully completed the physical assessment and history-taking course were recruited.

\section{SPREADING THE WORD}

For the outreach service to succeed, on-going promotional work was essential. This involved several strategies:

- Short presentations to all members of the multidisciplinary team prior to and throughout the staged introduction of the outreach service.

- Regular meetings were held with the ICU consultants to provide up-to-date information on the development of the service.

- Presentations about the service to consultants in each directorate.

- Presentation to junior doctors on their induction days and distribution of a pamphlet about the outreach service in their induction packs.

- Face-to-face networking with ward managers and nursing staff during which we asked them to identify what they would want from outreach and how their wards could benefit from the service. This served to give them ownership and responsibility in the success of the service.

- Identified educational link nurses for each directorate in order to identify specific ward needs.

- Liaison with nurse practitioners, physiotherapists and the pain team enabled us to complement their service and raise the profile of the outreach service in ward areas.

- Posters were distributed throughout the hospital, highlighting the referral mechanism, telephone and bleep numbers for contacting the outreach team.

- A monthly newsletter to update ward clinicians about the outreach service.

- Dissemination of information about the outreach team through the hospital magazine and website to ensure we reached out to all healthcare professionals at Queen Alexandra Hospital.

\section{IMPLEMENTATION OF THE SERVICE}

In order for the outreach team to gain the confidence and trust of the multidisciplinary team, the service was launched in two distinct phases. The first phase began on the 5th February 2001. During this phase, the team provided a follow-up service for all patients discharged from ICU and HDU, thus providing support, 
advice and education to ward clinicians caring for patients discharged to the ward. We saw this as an opportunity to smooth the transition for patients and their relatives (Leith 1998; Whittaker and Ball 2000). Three weeks later on 26th February 2001, phase two began and the referral service was implemented.

\section{FOLLOW-UP}

During the first five months, a total of 230 patients were followed-up after discharge from either ICU or HDU. A total of 730 visits were undertaken with each patient averaging three visits. Each visit lasted 18.6 minutes on average. There was no set format for the frequency of visits or number of days that patients would be followed-up; this was decided on an individual basis. The follow-ups enabled us to interface on a regular basis with the ward staff allowing continuing public relations' work. During the second five-month period, a total of 255 patients were seen, necessitating 1661 visits averaging 6.5 visits per patient. Our increased presence within the clinical ward areas exposed the team to the realities and issues faced by the ward nursing teams. It became evident that wards who had been exposed to the follow-up service were more likely to make formal referrals. This probably occurred as a result of the high profile of the team.

\section{REFERRALS}

Since commencement of the referral service, 293 patients have been referred, necessitating 1,021 visits. Each patient required approximately three visits with an average of 35 minutes per visit. In spite of the open referral system for all health care professionals, nursing staff initiated $74 \%$ of the referrals with the remainder arising from medical staff, physiotherapists and ICU itself. We had anticipated that this open referral criteria could have prompted some inappropriate calls, but this did not occur.

\section{THE REALITY}

We initially envisaged being predominantly involved with the educational and advisory facets of our role. However, it soon became apparent that the majority of our advice was of a medical nature with our principal role being a facilitator of treatment.

Our expectations of being supportive, educational and advisory proved to be both naïve and idealistic. Instead, we discovered that the needs of the wards were more varied than we were prepared for. Fundamental issues such as the recording and interpretation of observations along with the more complex problems of the peri-arrest patient all developed into the outreach remit. The majority of referrals were for hypoxic or hypotensive patients which tested the boundaries of the outreach team, as there was no provision for the team to prescribe oxygen and intravenous fluids.

Working alone and being aware of our limitations generated feelings of isolation and stress. In addition, we considered ourselves to be guests on the wards and were aware that the preconceptions regarding ICU practitioners could limit our success. As this was a new project, we needed to be accepted by the multidisciplinary team in order to be utilised in the future.

\section{ADDRESSING THE REALITY}

A purpose-built database has been developed, enabling the collection of extensive and detailed data relating to the level of activity and the clinical nature of the workload.
These data are analysed and disseminated at Trust and ward level with the aim of empowering clinicians to develop and implement strategies to address the issues highlighted. Suggestions for potential action included a universal observation chart, further education of staff and a scoring system such as a Modified Early Warning Score (MEWS). This is a patient severity score devised in the UK to highlight 'at risk' patients based on their physiological parameters.

The outreach team have now been involved in a variety of teaching initiatives and exchanges of information with all senior nurses on a monthly basis while remaining in constant communication with ward staff. These inaugural concepts have led to positive developments at ward level.

At a local level, we have increased our establishment to six nurses, so allowing time to undertake the following project work:

- To improve the continuity of care for patients discharged from critical care, we are in the process of formulating a new discharge summary based on the needs of ward staff.

- Following the occurrence of a number of re-admissions to critical care within two or three days post-discharge, all patients are now followed-up for a minimum of three days.

- The development of a Trust-approved policy that will enable members of the outreach team to supply and administer oxygen and intravenous fluids.

\section{THE FUTURE}

The key aim for the future is to expand the service in order to meet the demands of our increasing workload, having already performed 3,412 patient visits during the initial 10 months. One intention is to roster two nurses per shift. The aim is to provide either 24-hour cover or offer day cover for all acute care areas in the three hospitals within Portsmouth NHS Trust. However, these planned objectives will require extra funding, recruitment and training of staff. Our database will be developed to provide information at the level of guidelines strategic planning at Trust level, in particular the auditing of re-admission and cardiac arrest data. The Portsmouth and Southampton outreach teams have been working closely together and it is now vital that the concept and further development of outreach is promoted on a national and international level. We believe this can be achieved via minimum standards of data collection, ongoing networking, and conference presentations and through journal publications.

\section{REFERENCES}

Department of Health. (2000). Comprehensive Critical Care: A Review of Adult Critical Care Services. London: Department of Health.

Jarvis C. (2000). Physical Examination and Health Assessment. (3rd ed.) Philadelphia: Saunders.

Leith BA. (1998). Transfer anxiety in critical care patients and their family members. Critical Care Nurse; 18: 24-32.

Whittaker J, Ball C. (2000). Discharge from intensive care: a view from the ward. Intensive and Critical Care Nursing; 16: 135-143.

\section{FURTHER READING}

Garrard C, Young D. (1998). Suboptimal care of patients before admission to intensive care units. British Medical Journal; 316: 1841-1842.

Goldhill DR. (1997). Introducing the postoperative care team. British Medical Journal; 314: 389.

Goldhill DR, Worthington L, Mulcahy A, Tarling M, Sumner A. (1999). The patientat-risk team: identifying and managing seriously ill ward patients. Anaesthesia; 54: 853-860.

Goldhill D. (2000). Medical emergency teams. Care of the Critically Ill; 16: 209-212. Lee A, Bishop G, Hillman KM, Daffurn K. (1995). The medical emergency team. Anaesthesia and Intensive Care; 23: 183-186. 